\title{
Fiber Type-Specific Expression of Low-Density Lipoprotein Receptor-Related Protein 6 in Human Skeletal Muscles
}

\author{
Ikuko Takeda $^{a}$ Tetsuya Takahashi $^{a} \quad$ Kazuhide Ochi ${ }^{a}$ Takashi Kurashige $^{a}$ b \\ Yukari Shinozaki $^{a}$ Masahiro Nakamori ${ }^{a}$ Koji Arihiro ${ }^{b}$ Hirofumi Maruyama $^{a}$ \\ Masayasu Matsumoto ${ }^{a}$ \\ Departments of a Clinical Neuroscience and Therapeutics and ${ }^{\mathrm{b}}$ Anatomical Pathology, Graduate School of Biomedical and \\ Health Sciences, Hiroshima University, Hiroshima, Japan
}

\section{Key Words}

Low-density lipoprotein receptor-related protein 6 .

Muscle fiber type $\cdot$ Skeletal muscle $\cdot$ Wnt signaling

\begin{abstract}
Objective: Gene expression patterns differ in the two types of skeletal muscle fiber. The Wnt signaling pathway, which includes low-density lipoprotein receptor-related protein 6 (LRP6), has been associated with cell differentiation and glucose metabolism in skeletal muscles. We examined the relationships between muscle fiber types and LRP6 expression. Methods: Adenosine triphosphatase was assayed histochemically, and the levels of expression of LRP 6 and myosin were analyzed immunohistochemically, in frozen sections of muscle fiber obtained from 16 muscle biopsy samples. The expression pattern of LRP6 in C2C12 cells was assayed by immunocytochemistry. Results: LRP6 was expressed only in type II fibers. Type Ilc fibers showed variations in LRP6 expression. Expression of LRP6 was observed at the stage of myoblast differentiation. Conclusion: Antibody to LRP6 may be useful for identifying type II skeletal muscle fibers. LRP6 may influence glucose metabolism in type II fibers of human skeletal muscles.

(c) 2014 S. Karger AG, Basel
\end{abstract}

\section{KARGER}

(c) 2014 S. Karger AG, Basel

1015-2008/14/0812-0094\$39.50/0

E-Mail karger@karger.com

www.karger.com/pat

\section{Introduction}

Skeletal muscle is a heterogeneous tissue composed of type I and II fibers, which have different isoforms of myosin heavy and light chains [1]. The specification of isoform is modulated by neural [2] and hormonal factors [3]. Type I and II fibers can be distinguished by assaying myosin adenosine triphosphatase (ATPase), since the myosin isoforms have different ATPase staining patterns [4]. Type I, or slow-twitch, fibers contain myosin heavy chain (MHC)-I. Type II, or fast-twitch, fibers in humans can be categorized histochemically into two types, namely type IIa fibers, which contain MHC-IIa, and type IIb fibers, which contain MHC-IIx. Although mRNA transcripts of the MHC-IIb gene were observed in these fibers, expression of the MHC-IIb isoform has not been confirmed in human skeletal muscles [5].

Low-density lipoprotein (LDL) receptor-related protein (LRP) is a member of the LDL receptor family. While the role of the LDL receptor itself is limited to the regulation of cholesterol homeostasis by receptor-mediated endocytosis of lipoproteins, the LDL receptor family has additional functions. For example, LRP4, a member of the LRP family, binds agrin and forms complexes in neuromuscular junctions, thus playing a role in the formation 
and maintenance of neuromuscular junctions [6]. Patients with myasthenia gravis have autoantibodies against LRP4 which inhibit the aggregation of acetylcholine receptors [7].

LRP6, another member of the LDL receptor family, functions as a coreceptor of the Frizzled family of cell surface receptors and as part of the Wnt signaling pathway. Wnts bind to LRP6 and Frizzled receptors and initiate Wnt signaling, which mainly controls the turnover of $\beta$-catenin, leading to the activation of target gene transcription [8]. The Wnt signal pathway plays a critical role in the development of multicellular organisms, such as changes in cell phenotypes $[9,10]$ and transforming muscle fiber types [11]. LRP6 mutant mice die at birth and show many developmental abnormalities, including truncation of the axial skeleton and limb defects [12]. Although LRP6 may also regulate glucose metabolism in human skeletal muscles [13], little is known about its expression pattern in skeletal muscle. We therefore assessed the association between LRP6 expression and muscle fiber types in sections of human muscles and in $\mathrm{C} 2 \mathrm{C} 12$ cells.

\section{Materials and Methods}

\section{Subjects and Muscle Biopsies}

Biopsies of the biceps, quadriceps or tibial anterior muscles were obtained between 2002 and 2011 at Hiroshima University Hospital from 3 normal individuals, 2 patients with amyotrophic lateral sclerosis, 1 with Charcot-Marie-Tooth disease, 1 with polymyositis, 2 with dermatomyositis, 1 with distal myopathy with rimmed vacuoles, 2 with sporadic inclusion body myositis, 1 with dysferlinopathy and 2 with mitochondrial myopathy. All patients had been diagnosed by clinical history, neurological examination, electromyography and muscle biopsy findings. The biopsy samples were cut into $7-\mu \mathrm{m}$ frozen sections on a cryostat microtome at $-20^{\circ} \mathrm{C}$ and stored at $-80^{\circ} \mathrm{C}$. The study protocol was approved by the ethics committee of Hiroshima University, and all patients provided written informed consent. All samples were coded, and personal information was disassociated from the test results. All the data were analyzed anonymously.

\section{Immunohistochemistry and Western Blotting}

Frozen sections were added to a blocking solution (Protein Block, Serum-Free, DAKO, Glostrup, Denmark) and incubated for $30 \mathrm{~min}$ at room temperature. The sections were incubated overnight at $4{ }^{\circ} \mathrm{C}$ with primary antibodies against LRP6 (HPA029925, Sigma-Aldrich, St. Louis, Mo., USA; 1:150), fast skeletal myosin (ab7784, Abcam, Cambridge, UK; 1:150), Wnt3a (2721, Cell Signaling, Danvers, Mass., USA; 1:50), Wnt5a/b (2530, Cell Signaling; 1:50), Dishevelled (Dvl) 2 (HPA022914, Sigma-Aldrich; 1:20) and Dvl3 (SAB4200007, Sigma-Aldrich; 1:50), diluted in phosphate-buffered saline, followed by incubation for $2 \mathrm{~h}$ at room temperature with goat anti-rabbit antibody conjugated to
Alexa-488 (Life Technologies, Carlsbad, Calif., USA; 1:1,000) and goat anti-mouse antibody conjugated to Alexa-568 (Life Technologies; $1: 1,000)$. The sections were examined under a fluorescence microscope (BIOREVO BZ-9000, Keyence, Osaka, Japan).

In addition, immunohistochemistry was performed on serial sections using the peroxidase-conjugated polymer method (EnVision+ system-HRP, DAKO). The sections were incubated overnight at $4{ }^{\circ} \mathrm{C}$ with primary rabbit anti-LRP6 (HPA029925 and C5C7, Cell Signaling; 1:100), mouse anti-fast myosin, rabbit anti-Wnt3a, rabbit anti-Wnt5a/b, rabbit anti-Dvl2 and rabbit anti-Dvl3 antibodies, followed by incubation for $60 \mathrm{~min}$ at room temperature with anti-mouse IgG or anti-rabbit IgG (DAKO). Fast skeletal myosin represents the source of muscle fiber diversity and type II fibers [1]. The sections were subsequently incubated with 3,3'-diaminobenzidine (Vector Laboratories, Burlingame, Calif., USA), counterstained with hematoxylin and examined under a light microscope (Nikon E1000, Nikon, Tokyo, Japan).

The specificity of the anti-LRP6 antibody (HPA029925) was confirmed by antibody adsorption tests and Western blotting. In the adsorption tests, anti-LRP6 antibody (1:150) was incubated overnight at $4^{\circ} \mathrm{C}$ with a $160 \times$ molar concentration of LRP 6 peptide identical to the immunogen used to generate anti-LRP6 antibody (sc17984P, Santa Cruz Biotechnology, Dallas, Tex., USA). Serial sections were incubated with anti-LRP6 antibody, alone or with the peptide.

For Western blotting experiments, the biopsy samples were cut into small pieces weighing approximately $0.01 \mathrm{~g}$ each, homogenized in buffer $(50 \mathrm{~mm}$ Tris- $\mathrm{HCl}, \mathrm{pH} 7.4,140 \mathrm{mM} \mathrm{KCl}, 3 \mathrm{~mm}$ EDTA, $0.5 \%$ Triton X-100, $10 \mu \mathrm{g} / \mathrm{ml}$ aprotinin, $10 \mu \mathrm{g} / \mathrm{ml} \mathrm{leu-}$ peptin, $1 \mathrm{mM}$ PMSF) and centrifuged at $14,000 \mathrm{rpm}$ for $10 \mathrm{~min}$. C2C12 cells were scraped off the dish, added to lysis buffer (50 mM Tris- $\mathrm{HCl}$, pH 7.4, $150 \mathrm{~mm} \mathrm{NaCl}, 1 \mathrm{~mm}$ EDTA, 10\% glycerine, $1 \% \mathrm{NP}-40,10 \mu \mathrm{g} / \mathrm{ml}$ aprotinin, $10 \mu \mathrm{g} / \mathrm{ml}$ leupeptin, $1 \mathrm{mM}$ PMSF) and centrifuged at $14,000 \mathrm{rpm}$ for $10 \mathrm{~min}$. Soluble proteins were resolved by SDS-polyacrylamide gel electrophoresis and transferred to nitrocellulose membranes. Western blotting was performed by incubating the membranes overnight at $4^{\circ} \mathrm{C}$ with rabbit anti-LRP6 antibody (HPA029925; 1:1,000) or mouse anti- $\alpha$-tubulin antibody (Life Technologies; 1:1,000), followed by incubation with horseradish peroxidase-conjugated goat antimouse or anti-rabbit antibody (Santa Cruz Biotechnology; 1:5,000) and chemiluminescent detection. Adsorption tests of Western blots were performed by incubating the nitrocellulose membranes overnight at $4{ }^{\circ} \mathrm{C}$ with rabbit anti-LRP6 antibody (HPA029925) in the presence or absence of an $80 \times$ molar excess of LRP6 peptide.

\section{ATPase Activity}

Sections were preincubated in alkaline $(\mathrm{pH} 10.4)$ or acid $(\mathrm{pH}$ 4.2 or 4.6) solution and serially cross-stained for ATPase activity as described elsewhere, with modifications [14]. Fiber types were distinguished by their ATPase staining intensities. Digital images were collected from 3 fields, and each type of muscle fiber was counted.

\section{Cell Culture}

C2C12 cells (RIKEN BioResource Center, Ibaraki, Japan), a subclone of a mouse myoblast cell line, were grown in Dulbecco's modified Eagle's medium (DMEM; Life Technologies) supple- 
mented with $10 \%$ fetal bovine serum until they reached $60-80 \%$ confluence. The cells were differentiated for at least 7 days in DMEM containing $2 \%$ horse serum, with culture medium replaced every other day.

\section{Immunocytochemistry}

C2C12 cells were permeabilized with $0.2 \%$ Triton X-100 for 20 min, blocked with $10 \%$ bovine serum albumin and incubated with rabbit anti-LRP6 antibody (HPA029925; 1:1,000) and mouse antifast myosin antibody (1:200). The cells were washed and incubated with goat anti-rabbit antibody conjugated to Alexa Fluor 488 (1:200) and goat anti-mouse antibody conjugated to Alexa Fluor 568 (1:200). The cells were counterstained with Hoechst Dye 33258 (Life Technologies; 1:1,000) and examined by confocal laser scanning microscopy (LSM5 PASCAL, Carl Zeiss, Oberkochen, Germany) with a $60 \times$ oil immersion objective lens.

\section{Results}

Muscle biopsies showed variability in fiber size, with some fibers being hypotrophic. Immunofluorescence analysis showed coexpression of LRP6 and fast skeletal myosin in most muscle fibers of all 15 biopsy samples (fig. 1), indicating that they were type II fibers. In each LRP6-positive muscle fiber, LRP6 was expressed uniformly throughout the cytoplasm (fig. 1a, d, g, j, m). The same cytoplasmic expression pattern of LRP6 was observed when the sections were incubated with a second anti-LRP6 antibody (C5C7; online suppl. fig. 1; for all online suppl. material, see www.karger.com/ doi/10.1159/000357238). Several atrophic muscle fibers were positive for either fast myosin or LRP6. Assays using antibodies to other components of the Wnt signaling pathway, including Wnt3a, Wnt5a/b and Dvl2 and Dvl3 proteins, showed expression patterns different from those of LRP6, with staining not corresponding to specific fiber types (data not shown).

LRP6 expression patterns were also assayed by ATPase staining, which can distinguish among muscle fiber types in serial sections (fig. 2; online suppl. table 1). Type IIa and IIb fibers revealed by ATPase staining showed the same positive staining pattern as anti-LRP6 and anti-fast myosin antibodies. Type I fibers did not react with antiLRP6 or anti-fast myosin antibody. A few fibers showed mismatches between the expression of LRP6 and fast myosin. These mismatched fibers were type IIc, which reacted at both alkaline and acid $\mathrm{pH}$. Among the samples tested, $25-100 \%$ of type IIc fibers were positive for both LRP6 and fast skeletal myosin (online suppl. table 1).

Western blotting showed that the anti-LRP6 antibody recognized a single protein band with an approximate molecular weight of $220 \mathrm{kDa}$ (fig. 2e). The specificity of the anti-LRP6 antibody was assessed using an antibody adsorption test. Preincubation of anti-LRP6 antibody with peptide abolished the ability of the antibody to stain LRP6-positive muscle fibers in the serial sections (fig. 2f, g). Signals obtained with anti-LRP6 antibody plus peptide were weaker than signals obtained with anti-LRP6 antibody alone on Western blots, confirming the specificity of this anti-LRP6 antibody (online suppl. fig. 2).

We also investigated the relationship between LRP6 and fiber types using C2C12 cells. Differentiation of C2C12 cells usually begins after 2-4 days of culture in DMEM plus $2 \%$ horse serum, with maturation increasing after 7-14 days. We found that LRP6 and fast myosin were coexpressed in the cytoplasm of $\mathrm{C} 2 \mathrm{C} 12$ cells after 7 and 8 days of differentiation (fig. 3). The expression of LRP6 and fast myosin in C2C12 cells showed a muscle striation pattern. These results suggest that LRP6 expression in the cytoplasm is initiated 7 days after myoblast differentiation.

\section{Discussion}

This study showed that LRP6 was expressed only in type II fibers of normal and atrophic muscle. The antiLRP6 polyclonal antibody was useful in identifying and classifying human skeletal muscle fibers. Since myosin ATPase activity differs in the two types of human skeletal muscles, which differ in their speed of contraction [15], ATPase histochemistry is used to distinguish these muscle types. In addition, immunohistochemical staining with anti-MHC monoclonal antibodies has been used to delineate fiber types in human skeletal muscle [1]. Our findings indicate that immunohistochemistry with polyclonal anti-LRP6 antibody may be as useful in distinguishing among fiber types as ATPase activity and immunohistochemistry with anti-MHC antibody.

We observed differences among type IIc fibers, which showed stable ATPase activity at both alkaline and acid $\mathrm{pH}$. Type IIc fibers are regenerated fibers and represent a heterogeneous population of fibers containing both MHC-I and MHC-IIa [16]. Thus, it was not surprising that the level of expression of LRP6 in these fibers varied.

Although LDL receptor proteins are considered lipid or lipid-protein transport proteins, emerging evidence suggests that these receptors play a role in cell signaling and influence cell functions. For example, the LDL receptor protein LRP4 is crucial not only for Wnt signaling [17] but also for the formation of neuromuscular junctions 

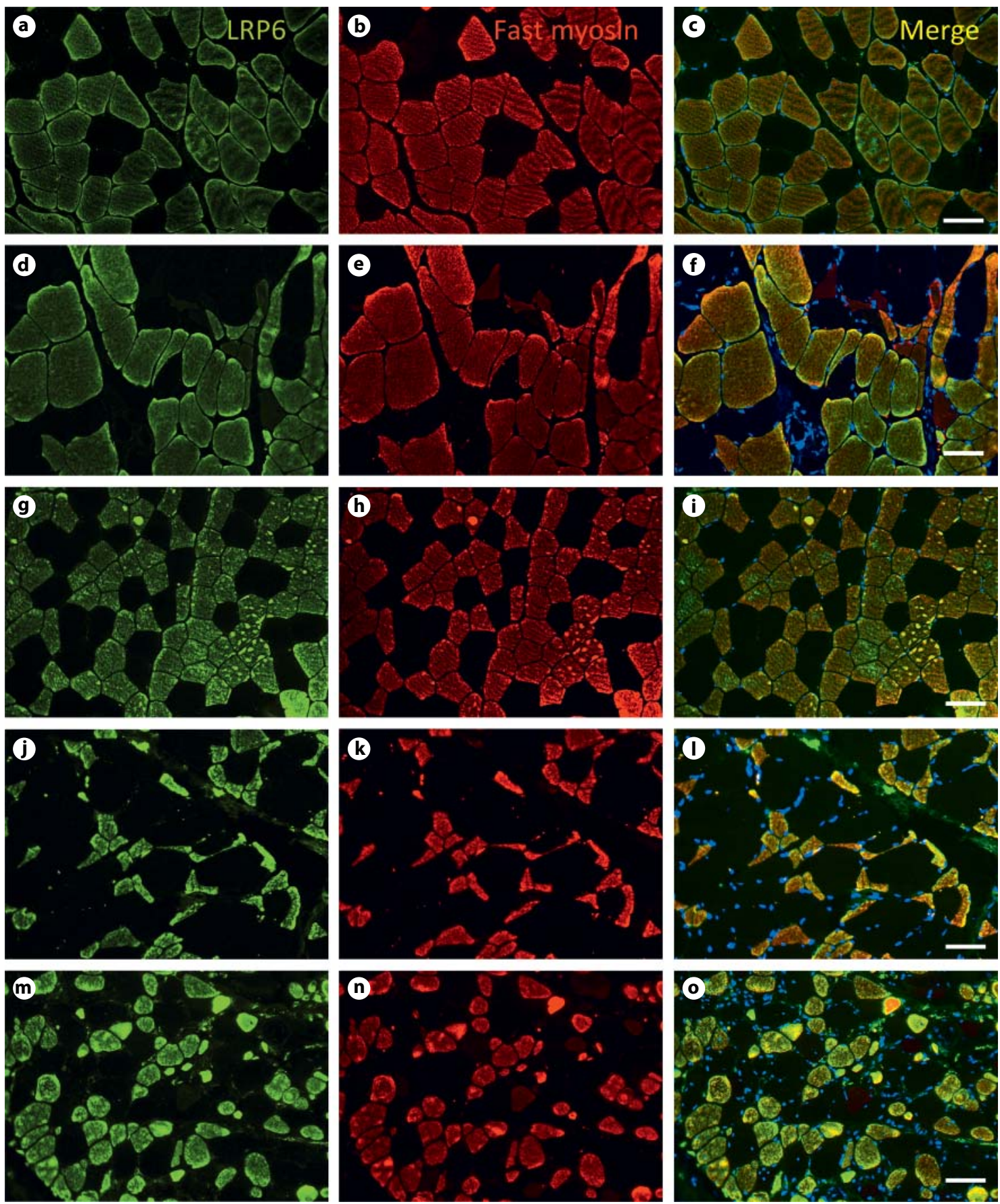

Fig. 1. Comparative expression of LRP6 in different muscle fiber types. a-o Representative expression of LRP6 and fast skeletal myosin. Muscle fibers from normal individuals (a-c) and from patients with amyotrophic lateral sclerosis $(\mathbf{d}-\mathbf{f})$, mitochondrial myopathy $(\mathbf{g}-\mathbf{i})$, polymyositis $(\mathbf{j}-\mathbf{I})$ and sporadic inclusion body myositis $(\mathbf{m}-\mathbf{o})$ were immunostained with antibodies against LRP6 $(\mathbf{a}, \mathbf{d}, \mathbf{g}, \mathbf{j}, \mathbf{m})$ or fast skeletal myosin $(\mathbf{b}, \mathbf{e}, \mathbf{h}, \mathbf{k}, \mathbf{n})$ and subsequently counterstained with Hoechst Dye $33258(\mathbf{c}, \mathbf{f}, \mathbf{i}, \mathbf{I}, \mathbf{o})$. Bars $=50 \mu \mathrm{m}$. 
Fig. 2. LRP6 expression and ATP activity in sections from patients with distal myopathy with rimmed vacuoles. a-d Sections were incubated with anti-LRP6 antibody (a) and for ATP activity, following preincubation at pH 10.4 (b), pH 4.2 (c) or pH 4.6 (d). Type I fibers (I) showed high ATPase activity after preincubation at either $\mathrm{pH} 4.2$ or 4.6 but low ATPase activity after preincubation at $\mathrm{pH}$ 10.4. Type IIa fibers (IIa) showed a strong reaction after preincubation at $\mathrm{pH}$ 10.4 but a weak reaction at $\mathrm{pH} 4.2$ and 4.6. Type IIb fibers (IIb) also showed a strong reaction after preincubation at $\mathrm{pH} 10.4$ but no reaction at $\mathrm{pH} 4.2$ and a moderate reaction at $\mathrm{pH}$ 4.6. Type IIc fibers (IIc) reacted after incubation at both alkaline and acid pH. Bars $=50 \mu \mathrm{m}$. e Western blotting of samples from human skeletal muscle (lane 1) and $\mathrm{C} 2 \mathrm{C} 12$ cells grown for 7 days in $2 \%$ horse serum (lane 2). Anti-LRP6 antibody recognized one band at $220 \mathrm{kDa}$. f, g Serial sections of muscle fibers were stained with antibody to LRP6, in the presence (f) or absence $(\mathbf{g})$ of LRP6 peptide. An adsorption test showed no immunoreactivity to LRP6 in the muscle fibers treated with antibody and LRP6 peptide (arrowheads). Each section was counterstained with hematoxylin. Bars $=50 \mu \mathrm{m}$.

Fig. 3. Expression of LRP6 in C2C12 cells. a-f LRP6 and fast myosin expression at differential stages. C2C12 cells were incubated in differentiation medium for 7 (ac) and 8 (d-f) days, fixed and stained with antibodies against LRP6 (a, d) and fast myosin (b, e) and subsequently counterstained with Hoechst Dye 33258 (c, f). Bars $=20 \mu \mathrm{m}$.
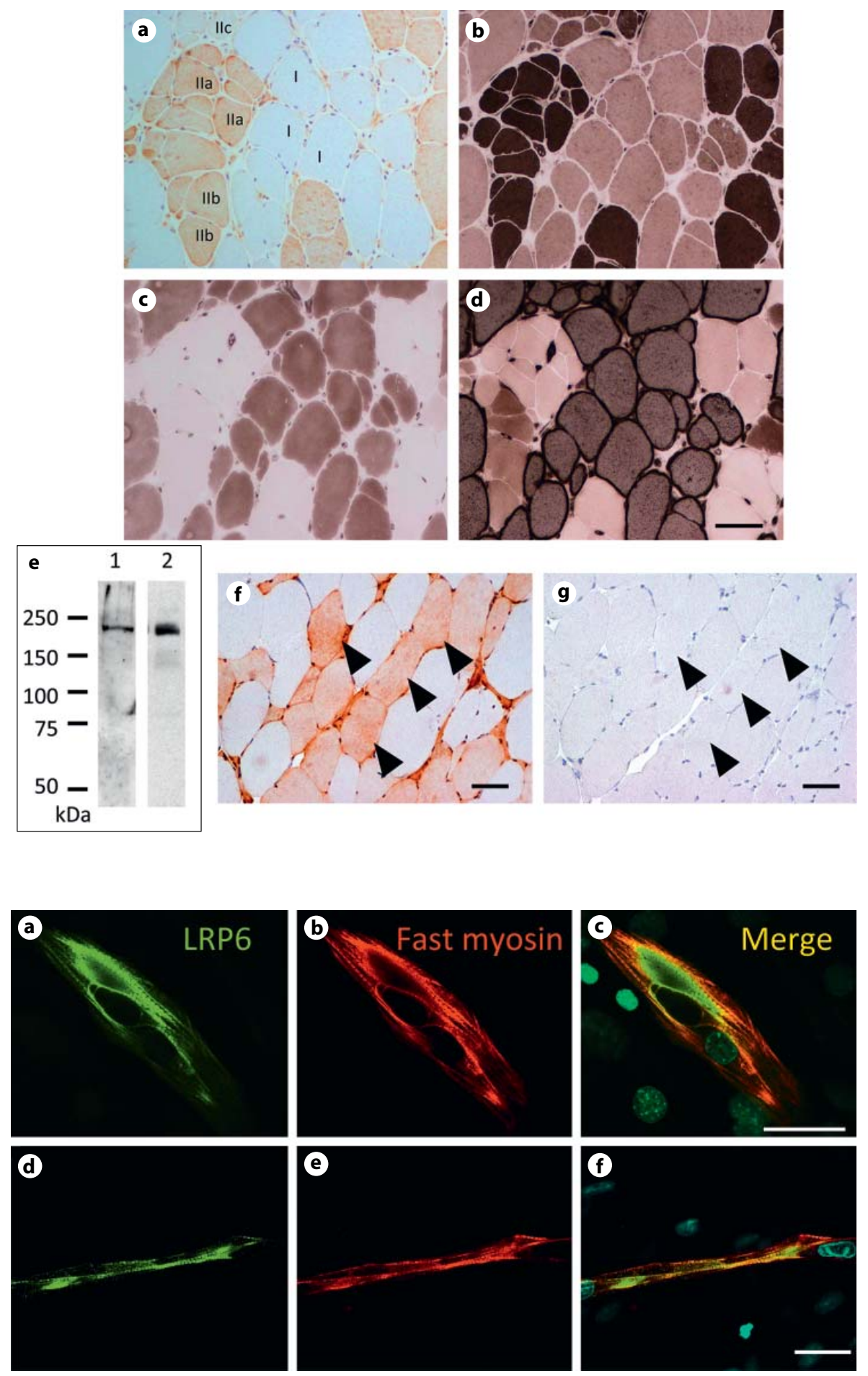

[6]. Presumably, therefore, LRP6 may have multiple functions in skeletal muscles. Wnt signaling regulates myogenic differentiation [18] and alters the ratio of slow and fast fibers. Several members of the Wnt pathway have been found to induce cell differentiation [19] and to in- crease the number of fibers expressing MHC-I and/or MHC-II [11]. In contrast, we observed no relationship between the level of expression of LRP6 and that of other members of the Wnt signaling pathway in human skeletal muscle. LRP6 may also regulate body fat and glucose ho- 
meostasis in adipose and hepatic tissues [20] and the expression of insulin receptors in skeletal muscles [13, 21]. Because type I fibers have a higher content of glucose transporter-4 protein, a key molecule for glucose uptake, than type II fibers, type I fibers allow greater glucose uptake [22]. In contrast, glucose transporter-4 protein does not play a major role in regulating the rate of glucose uptake by type II fibers, suggesting that the mechanisms of glucose uptake differ in type I and type II fibers. The interaction between LRP6 and caveolin-1 causes aerobic glycolysis by stimulating insulin-like growth factor-I receptor and insulin receptor signaling $[13,23]$. Caveolin-1 is upregulated in type II fibers by exercise [24]. The fiber type-specific expression of LRP6 may indicate that LRP6 influences type II fiber-specific glucose metabolism.

\section{Acknowledgments}

We thank the patients for their kind participation. We are grateful to Ms. M. Sasanishi, Ms. Y. Furuno and Ms. A. Hironaka for their technical assistance. We also thank the Research Center for Molecular Medicine of Hiroshima University for the use of their facilities. This work was supported by a grant from the Smoking Research Foundation, Tokyo, Japan.

\section{References}

$\checkmark 1$ Schiaffino S, Reggiani C: Molecular diversity of myofibrillar proteins: gene regulation and functional significance. Physiol Rev 1996;76: 371-423.

$\checkmark 2$ Buller AJ, Eccles JC, Eccles RM: Interactions between motoneurones and muscles in respect of the characteristic speeds of their responses. J Physiol 1960;150:417-439.

-3 Chin ER, Olson EN, Richardson JA, Yang Q, Humphries C, Shelton JM, Wu H, Zhu W, Bassel-Duby R, Williams RS: A calcineurindependent transcriptional pathway controls skeletal muscle fiber type. Genes Dev 1998;12: 2499-2509.

-4 Termin A, Staron RS, Pette D: Myosin heavy chain isoforms in histochemically defined fiber types of rat muscle. Histochemistry 1989; 92:453-457.

5 Horton MJ, Brandon CA, Morris TJ, Braun TW, Yaw KM, Sciote JJ: Abundant expression of myosin heavy-chain IIb RNA in a subset of human masseter muscle fibres. Arch Oral Biol 2001;46:1039-1050.

6 Weatherbee SD, Anderson KV, Niswander LA: LDL-receptor-related protein 4 is crucial for formation of the neuromuscular junction. Development 2006;133:4993-5000.

7 Pevzner A, Schoser B, Peters K, Cosma NC, Karakatsani A, Schalke B, Melms A, Kroger S: Anti-LRP4 autoantibodies in AChR- and MuSK-antibody-negative myasthenia gravis. J Neurol 2012;259:427-435.

$\checkmark 8$ Behrens J, von Kries JP, Kuhl M, Bruhn L, Wedlich D, Grosschedl R, Birchmeier W: Functional interaction of beta-catenin with the transcription factor LEF-1. Nature 1996; 382:638-642.
9 Carthy JM, Garmaroudi FS, Luo Z, McManus BM: Wnt3a induces myofibroblast differentiation by upregulating TGF-beta signaling through SMAD2 in a beta-catenin-dependent manner. PLoS One 2011;6:e19809.

10 George SJ: Regulation of myofibroblast differentiation by convergence of the Wnt and TGF-beta1/Smad signaling pathways. J Mol Cell Cardiol 2009;46:610-611.

-11 Anakwe K: Wnt signalling regulates myogenic differentiation in the developing avian wing. Development 2003;130:3503-3514.

12 Pinson KI, Brennan J, Monkley S, Avery BJ, Skarnes WC: An LDL-receptor-related protein mediates Wnt signalling in mice. Nature 2000;407:535-538.

13 Singh R, De Aguiar RB, Naik S, Mani S, Ostadsharif K, Wencker D, Sotoudeh M, Malekzadeh R, Sherwin RS, Mani A: LRP6 enhances glucose metabolism by promoting TCF7L2-dependent insulin receptor expression and IGF receptor stabilization in humans. Cell Metab 2013;17:197-209.

14 Brooke MH, Kaiser KK: Three 'myosin adenosine triphosphatase' systems: the nature of their $\mathrm{pH}$ lability and sulfhydryl dependence. J Histochem Cytochem 1970;18:670-672.

15 Bárány M: ATPase activity of myosin correlated with speed of muscle shortening. J Gen Physiol 1967;50(suppl):197-218.

-16 Neunhauserer D, Zebedin M, Obermoser M, Moser G, Tauber M, Niebauer J, Resch H, Galler S: Human skeletal muscle: transition between fast and slow fibre types. Pflugers Arch 2011;461:537-543.

17 Simon-Chazottes D, Tutois S, Kuehn M, Evans M, Bourgade F, Cook S, Davisson MT, Guenet JL: Mutations in the gene encoding the low-density lipoprotein receptor LRP4 cause abnormal limb development in the mouse. Genomics 2006;87:673-677.
18 Han XH, Jin YR, Seto M, Yoon JK: A WNT/ beta-catenin signaling activator, R-spondin, plays positive regulatory roles during skeletal myogenesis. J Biol Chem 2011;286:1064910659.

19 Tanaka S, Terada K, Nohno T: Canonical Wnt signaling is involved in switching from cell proliferation to myogenic differentiation of mouse myoblast cells. J Mol Signal 2011;6:12.

20 Liu W, Singh R, Choi CS, Lee HY, Keramati AR, Samuel VT, Lifton RP, Shulman GI, Mani A: Low density lipoprotein (LDL) receptor-related protein 6 (LRP6) regulates body fat and glucose homeostasis by modulating nutrient sensing pathways and mitochondrial energy expenditure. J Biol Chem 2012;287:7213-7223.

21 Mani A, Radhakrishnan J, Wang H, Mani MA, Nelson-Williams C, Carew KS, Mane S, Najmabadi H, Wu D, Lifton RP: LRP6 mutation in a family with early coronary disease and metabolic risk factors. Science 2007;315: 1278-1282.

22 Henriksen EJ, Bourey RE, Rodnick KJ, Koranyi L, Permutt MA, Holloszy JO: Glucose transporter protein content and glucose transport capacity in rat skeletal muscles. Am J Physiol 1990;259:E593-E598.

23 Tahir SA, Yang G, Goltsov A, Song KD, Ren C, Wang J, Chang W, Thompson TC: Caveolin-1-LRP6 signaling module stimulates aerobic glycolysis in prostate cancer. Cancer Res 2013;73:1900-1911.

24 Oh YS, Kim HJ, Ryu SJ, Cho KA, Park YS, Park H, Kim M, Kim CK, Park SC: Exercise type and muscle fiber specific induction of caveolin-1 expression for insulin sensitivity of skeletal muscle. Exp Mol Med 2007;39:395-401. 